\title{
Effects of Concurrent Strength and Endurance Training on Speed
}

\author{
Dr. D. Maniazhagu"
}

Assistant Professor, Department of Physical Education and Health Sciences, Alagappa University, Karaikudi, Tamilnadu, India

DOI: $10.36348 /$ jaspe.2020.v03i07.003

| Received: 10.07 .2020 | Accepted: 18.07 .2020 | Published: 26.07.2020

*Corresponding author: Dr. D. Maniazhagu

Abstract

The aim of the present study was to know the effects of concurrent strength and endurance training on speed of junior athletes. Thirty school junior athletes from Alagappa Model Higher Secondary School, Karaikudi were randomly selected as subjects. The age of the subjects ranged between 15 to 17 years. The thirty subjects were divided into three equal groups. The experimental group-1 $\left(\mathrm{n}=10, \mathrm{ST}_{\mathrm{b}} \mathrm{ET}\right)$ underwent strength training before endurance training, the experimental group-2 $\left(\mathrm{n}=10, \mathrm{ST}_{\mathrm{a}} \mathrm{ET}\right)$ underwent strength training after endurance training and group 3 served as control group $(n=10, C G)$. The speed was chosen as criterion variables and tested by 50 meters run. The selected two treatment group's were performed three days in a week for the period of nine weeks, as per the stipulated training program. The speed was tested before and after the training period. The collected pre and post data was critically analyzed with apt statistical tool of one way analysis of co-variance.The ability of speed have shown better in both treatment groups than the control group.

Keywords: 1.Concurrent training, 2.Strength, 3.Endurance, 4. Speed, 5. Ancova.

Copyright @ 2020: This is an open-access article distributed under the terms of the Creative Commons Attribution license which permits unrestricted use, distribution, and reproduction in any medium for non-commercial use (NonCommercial, or CC-BY-NC) provided the original author and source are credited.

\section{INTRODUCTION}

Athletes to achieve adaptations specific to both forms of exercise commonly perform concurrent training programs involving strength and endurance exercises. Research investigating the effects of concurrent training has typically compared changes in strength and endurance variables after strength training, endurance training or concurrent strength and endurance training. Concurrent strength and endurance training is undertaken by numerous athletes in various sports in an effort to achieve adaptations specific to both forms of training. Literature findings to date, investigating the neuromuscular adaptations and performance improvements associated with concurrent strength and endurance training (referred to as concurrent training) have produced inconsistent results. Some studies have shown that concurrent training inhibits the development of strength and power, but does not affect the development of aerobic fitness when compared to either mode of training alone. Other studies have shown that concurrent training has no inhibitory effect on the development of strength and endurance. Strength and endurance training regimes represent and induce distinctly different adaptive responses when performed individually. Typically, strength-training programs involve large muscle group activation of high-resistance low-repetition exercises to increase the force output ability of skeletal muscle [1]. In contrast, endurance-training programs utilize lowresistance, high-repetition exercises such as running or cycling to increase maximum $\mathrm{O}_{2}$ uptake $\left(\mathrm{VO}_{2} \max \right)$. Accordingly, the adaptive responses in skeletal muscle to strength and endurance training are different and sometimes opposite [2]. Strength training has been reported to cause muscle fibre hypertrophy, associated with an increase in contractile protein, which contributes to an increase in maximal contractile force [1]. Strength training also reduces mitochondrial density and suppresses oxidative enzymes activity which can cause impede endurance capacity, but has minimal impact on capillary density or in the conversion of muscle fibre types from fast twitch (type II fibres) to slow twitch (type I fibres) [3, 1]. In contrast, endurance training usually causes little or no muscle fibre hypertrophy, but it does induce increases in mitochondria content, citric acid enzymes, oxidative capacity and the possibility of muscle fibre conversion from fast twitch to slow twitch $[4,3,14]$.

\section{MATERIALS AND METHODS}

The study was formulated as pre and posttest random group design, in which thirty junior athletes were randomly assigned into three equal groups. During training, the experimental groups underwent their 
respective training as per the schedule. Control group maintained normal activities.

\section{STATISTICAL ANALYSIS}

The analysis of covariance (ANCOVA) was done for finding significant adjusted posttest mean different of groups on speed after eliminating the effect due to initial pre test scores. Scheffe's Post Hoc test was used to find out pair-wise comparisons between groups. To test the hypothesis 0.05 level of significant was fixed in this study.

\section{Training Approaches}

The following tables show the detailed training program for the period of nine weeks. The total duration of each was 90 minutes. As far as the training variable is concern the frequency was fixed 3 days.

EXPERIMENTAL GROUP - I

(Strength training before Endurance training)

$1-3$ WEEKS
\begin{tabular}{|l|l|l|}
\hline Intensity & $:$ & Low \\
\hline Frequency & $:$ & 3 days / wk \\
\hline Duration & $:$ & 3 week \\
\hline Stations /Circuit & $:$ & 6 exercise stations - clockwise order \\
\hline Duration of Exercise in each Station & $:$ & 15 seconds \\
\hline Set & $:$ & One \\
\hline Rest & $:$ & 30 sec (in between Stations) \\
\hline
\end{tabular}

ENDURANCE TRAINING

\begin{tabular}{|c|c|c|c|}
\hline Weeks & Exercises & Intensity & Repetitions \\
\hline 1-3 weeks & Extensive Method Run - 1 KM & Low & Single \\
\hline
\end{tabular}

\begin{tabular}{|c|c|c|}
\hline \multicolumn{3}{|c|}{ 4 - 6 WEEKS } \\
\hline Intensity & $:$ & Moderate \\
\hline Frequency & : & 3 days / wk \\
\hline Duration & : & 3 week \\
\hline Stations /Circuit & : & 6 exercise stations - clockwise order \\
\hline Duration of Exercise in each Station & : & 45 seconds \\
\hline Set & : & One \\
\hline Rest & : & 30 seconds (in between Stations) \\
\hline
\end{tabular}

ENDURANCE TRAINING
\begin{tabular}{|c|c|c|c|}
\hline Weeks & Exercises & Intensity & Repetitions \\
\hline 4-6 weeks & Extensive Method $-1.5 \mathrm{KM}$ & Moderate & Single \\
\hline
\end{tabular}

\begin{tabular}{|c|c|c|}
\hline \multicolumn{3}{|c|}{7 - 9 WEEKS } \\
\hline Intensity & $:$ & Moderate \\
\hline Frequency & : & 3 days $/ w k$ \\
\hline Duration & $:$ & 3 week \\
\hline Stations /Circuit & $:$ & 6 exercise stations - clockwise order \\
\hline Duration of Exercise in each Station & $:$ & 60 seconds \\
\hline Set & $:$ & One \\
\hline Rest & : & 30 seconds (in between Stations) \\
\hline
\end{tabular}

ENDURANCE TRAINING

\begin{tabular}{|c|l|l|c|}
\hline Weeks & \multicolumn{1}{|c|}{ Exercises } & Intensity & Repetitions \\
\hline $7-9$ weeks & Intensive Method - 2 KM & Moderate & Single \\
\hline
\end{tabular}

\section{Circuit Activities}

Push-ups, High-knee action, skipping, Vertical jump, Squat jump, Jumping Jog. Note: After Endurance training the Experimental Group II immediately shifted to strength training. 
EXPERIMENTAL GROUP - II

(Strength training After Endurance Training)

\section{1 - 3 WEEKS}

Endurance training

\begin{tabular}{|c|c|c|c|}
\hline Weeks & Exercises & Intensity & Repetitions \\
\hline 1-3 weeks & Extensive Method Run - 1 KM & Low & Single \\
\hline
\end{tabular}

\begin{tabular}{|c|c|c|}
\hline \multicolumn{3}{|c|}{ Strength Training (Circuit Training) } \\
\hline Intensity & $:$ & Low \\
\hline Frequency & $:$ & 3 days / wk \\
\hline Duration & $:$ & 3 week \\
\hline Stations /Circuit & $:$ & 6 exercise stations - clockwise order \\
\hline Duration of Exercise in each Station & : & 15 seconds \\
\hline Set & : & One \\
\hline Rest & : & 30 seconds (in between Stations) \\
\hline
\end{tabular}

\section{4 - 6 WEEKS}

Endurance training

\begin{tabular}{|c|c|c|c|}
\hline Weeks & Exercises & Intensity & Repetitions \\
\hline 4-6 weeks & Extensive Method - 1.5 KM & Moderate & Single \\
\hline
\end{tabular}

\begin{tabular}{|l|c|l|}
\hline Intensity & $:$ & Moderate \\
\hline Frequency & $:$ & 3 days / wk \\
\hline Duration & $:$ & 3 week \\
\hline Stations /Circuit & $:$ & 6 exercise stations - clockwise order \\
\hline Duration of Exercise in each Station & $:$ & 30 seconds \\
\hline Set & $:$ & One \\
\hline Rest & $:$ & 30 seconds (in between Stations) \\
\hline
\end{tabular}

7 - 9 WEEKS

Endurance training

\begin{tabular}{|c|c|l|c|}
\hline Weeks & Exercises & Intensity & Repetitions \\
\hline 7-9 weeks & Intensive Method - 2 KM & Moderate & Single \\
\hline
\end{tabular}

\begin{tabular}{|l|c|l|}
\hline Intensity & $:$ & Moderate \\
\hline Frequency & $:$ & 3 days / wk \\
\hline Duration & $:$ & 3 week \\
\hline Stations /Circuit & $:$ & 6 exercise stations - clockwise order \\
\hline Duration of Exercise in each Station & $:$ & 45 seconds \\
\hline Set & $:$ & One \\
\hline Rest & $:$ & 30 seconds (in between Stations) \\
\hline
\end{tabular}

Circuit Activities: Push-ups, High-knee action, skipping, Vertical jump, Squat jump, Jumping Jog. Note: After Endurance training the Experimental Group II immediately shifted to strength training

\section{RESULTS}

Table-1: The results of analysis of covariance on speed of different groups

(Scores in seconds)

\begin{tabular}{|c|c|c|c|c|c|c|c|c|c|}
\hline \multicolumn{2}{|l|}{ Test Conditions } & $\begin{array}{l}\text { G-1 } \\
\text { ST }_{b} \text { ET }\end{array}$ & $\begin{array}{l}\text { G-2 } \\
\text { ST }_{\mathrm{a}} \text { ET }\end{array}$ & $\begin{array}{l}\text { G-3 } \\
\text { CG }\end{array}$ & SV & SS & Df & MS & 'F' Ratio \\
\hline \multirow{2}{*}{ Pre test } & Mean & 10.99 & 10.98 & 10.95 & $\mathrm{~B}$ & 0.008 & 2 & 0.004 & \multirow{2}{*}{0.01} \\
\hline & S.D. & 0.72 & 0.62 & 0.5 & $\mathrm{~W}$ & 10.58 & 27 & 0.392 & \\
\hline \multirow{2}{*}{ Post test } & Mean & 9.61 & 9.38 & 10.96 & $\mathrm{~B}$ & 14.4 & 2 & 7.2 & \multirow{2}{*}{$54.12 *$} \\
\hline & S.D. & 0.28 & 0.28 & 0.51 & $\mathrm{~W}$ & 3.6 & 27 & 0.13 & \\
\hline \multirow{2}{*}{$\begin{array}{l}\text { Adjusted post } \\
\text { test }\end{array}$} & \multirow{2}{*}{ Mean } & \multirow{2}{*}{9.61} & \multirow{2}{*}{9.38} & \multirow{2}{*}{10.97} & $\mathrm{~B}$ & 14.68 & 2 & 7.34 & \multirow{2}{*}{$107.94 *$} \\
\hline & & & & & $\mathrm{W}$ & 1.77 & 26 & 0.068 & \\
\hline
\end{tabular}


The pretest mean and standard deviation on speed scores G1, G2, and G3 were 10.99 $\pm 0.72,10.98 \pm$ 0.62 and $10.95 \pm 0.5$ respectively. The obtained pretest $\bar{F}$ value of 0.01 was lesser than the required table $F$ value 0.03 . Hence the pretest means value of strength training before endurance training, strength training after endurance training and control group on speed before start of the respective treatments were found to be insignificant at 0.05 level of confidence for the degrees of freedom 2 and 27. Thus this analysis confirmed that the random assignment of subjects into three groups were successful. The post test mean and standard deviation on speed of G1, G2 and G3 were $9.61 \pm 0.28$ $9.38 \pm 0.23$ and $10.96 \pm 0.51$ respectively. The obtained post test $\mathrm{F}$ value of $54.12 *$ was higher than the required table $\mathrm{F}$ value of 3.37 . Hence the post test means value of strength training before endurance training and strength training after endurance training on speed was found to be significant at 0.05 level of confidence for the degrees of freedom 2 and 27. The results prove that selected two training interventions namely strength training before endurance training, strength training after endurance training was produced significant improvement rather than the control group of the sample populations. The adjusted posttest means on speed scores of G1, G2 and G3 were 9.61, 9.38 and 10.97 respectively. The obtained adjusted posttest $\mathrm{F}$ value of $107.94 *$ was higher than the required table $\mathrm{F}$ value of 3.35 .

Hence the adjusted posttest means value of strength training before endurance training, strength training after endurance training on speed was found to be significant at 0.05 level of confidence for the degrees of freedom 2 and 26. The results confirm that the selected two training interventions strength training before endurance training, strength training after endurance training on speed was produced significant difference among the groups.In order to find out the superiority effects among the treatment and control groups the Seheffe's post hoc test were administered. The outcomes of the same are presented in the table I (a).

Table- 1 (a): Scheffe's post hoc test means differences on speed among three groups (Scores in seconds)

\begin{tabular}{|c|c|c|c|c|}
\hline $\begin{array}{c}\text { G- 1 } \\
\mathbf{S T}_{\mathbf{b}} \text { ET }\end{array}$ & $\begin{array}{c}\text { G- 2 } \\
\mathbf{S T}_{\mathbf{a}} \text { ET }\end{array}$ & $\begin{array}{c}\text { G- 3 } \\
\mathbf{C ~ G}\end{array}$ & Mean Differences & Confidence Interval Value \\
\hline 9.61 & 9.38 & - & 0.22 & 0.371 \\
\hline 9.61 & - & 10.97 & $1.363^{*}$ & 0.371 \\
\hline & 9.38 & 10.97 & $1.582^{*}$ & 0.371 \\
\hline
\end{tabular}

* Significant at .05 level of confidence.

\section{Pair wise comparaison test on speed}

Table I (a) shows the paired mean differences of strength training before endurance training, strength training after endurance training and control group on speed. The paired wise comparisons results as follows. First comparison: Group 1 and 2: The pair wise mean difference of group 1 and group 2 values 0.22 was lesser than the confidential value of 0.371 . Hence the first comparison was insignificant. The results of this comparison clearly proved that strength training before endurance training and strength training after endurance training were produced better results in speed than the control group. However both training have produced similar effects on speed. Second comparison: Group 1 and 3: The pair wise mean difference of group 1 and group 3 values 1.363 was higher than the confidential value of 0.371 . Hence the second comparison was significant. The results of this comparison clearly proved that strength training before endurance training has produced greater improvements on speed than the control group. Third comparison: Group 2 and 3: The pair wise mean difference of group 2 and group 3 values 1.582 was higher than the confidential value of 0.371 . Hence the third comparison was significant. The results of this comparison clearly proved that strength training after endurance training has produced greater improvements on speed than the control group.The adjusted posttest mean deference of experimental and control group value graphically represented in the figure.

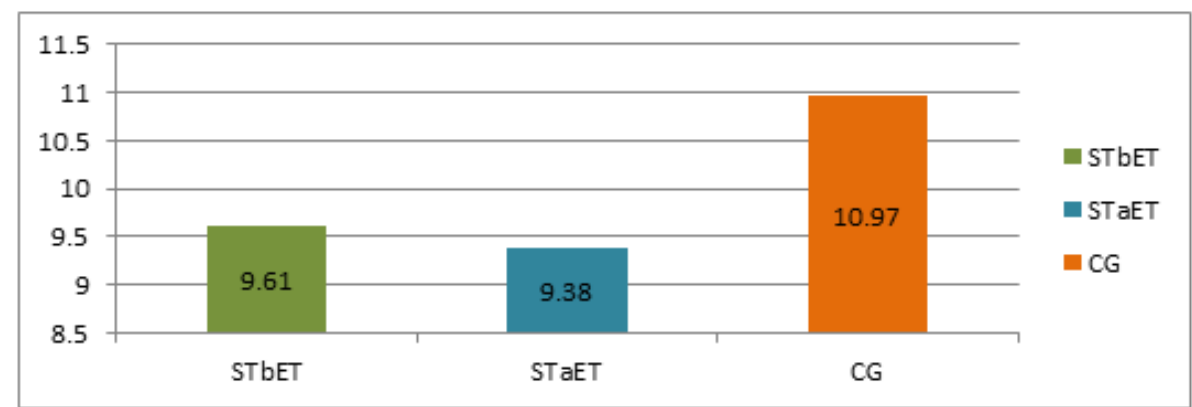

Fig-1: Show the Adjusted Post Test Mean Values of Experimental and Control Groups On Speed (Scores In Seconds) 


\section{DISCUSSION ON FINDINGS}

Concurrent training studies investigating endurance and strength performance to date have shown mixed results. Nelson et al. [3] reported that improvements in maximal oxygen uptake $\left(\mathrm{VO}_{2} \max \right)$ during the second half of a 20 -week programme were compromised when strength training was implemented into an endurance program. In contrast, a number of studies have found no interference to strength or endurance development because of concurrent training $[1,4,5]$. Sale et al. [6] suggested that resistance training performed on the same day as endurance training may impede strength development when compared to training for either on separate days. Overall, the most consistent finding from concurrent training literature to emerge was that concurrent training can inhibit strength and power when compared to strength training alone [79]. However, no studies have demonstrated or suggested possible mechanisms for the observed reductions in strength development when utilizing a concurrent program. Strength training is defined as a low number of repetitions performed on a load that is of high resistance, producing a maximal or near-maximal contraction $[10,1]$ In contrast, endurance training is defined as repeated sub-maximal contractions with loads of low resistance $[10,1]$. When performed independently, these four distinct forms of training induce for the most part, opposite physiological adaptations within the muscle. Therefore, the adaptation to training that the muscle endures is specific to the training stimulus. Initial gain muscle strength during the first few week of training do not show a concomitant in muscle size or muscle cross sectional area $[11,12,6]$. Maniazhagu, D. Susai Arokia Malar [13, 14] found twenty four weeks of concurrent training effects improve the nature of speed.

The quality of the muscle - specifically, type of the muscle proteins that make of the myosin filament changes, but not enough protein is accumulated in the cell to create increase in muscle fiber size. Within several weeks, however, myofibril proteins start to be added to muscle fibers, and increases in muscle fiber size are observed at about 8 to 12 weeks of training. The majority of concurrent training studies have demonstrated that strength development is inhibited during concurrent strength and endurance training programs. However, few authors have attempted to identify why this phenomenon exists. Possible mechanisms have been suggested, which include overtraining, conflicting physiological adaptations, muscle fiber type transformations, hypertrophy, endocrine changes, and muscular or neural adaptations. After analyzing the statistical end results the researcher found that the selected training groups have significantly improved the quality of speed from the base line to post interventions. The pre to post intervention was present as follows. The strength training before endurance training, group from pre $(10.99 \pm 0.72)$, to post $(9.61 \pm 0.28)$ and strength training after endurance training from pre $(10.98 \pm 0.62)$ to post $(9.38 \pm 0.23)$ have significantly changed the pre to post results. The present study demonstrates an increase in speed performance of $0.0138 \%$ and $0.016 \%$ for strength training before endurance training, strength training after endurance training. The result of this study proves that both training increased the quality of speed significantly over the eight weeks training when comparing control group. However, the strength training after endurance training would produce better improvement than the other training group namely strength training after endurance training. Further strength training after endurance training has produces better improvement on speed than the control group. The control group did not show any significant changes on speed. In the present study findings in line with above said many study findings.

\section{CONCLUSION}

The strength training before endurance training, strength training after endurance training group have produced significant improvement on speed, than control group of junior sprinters' responses to the effects of nine weeks training interventions.

\section{ACKNOWLEDGEMENT}

Dr. D. Maniazhagu thanks for the financial support of MHRD-UGC, RUSA-Phase 2.0 grant No.F, 24-5/2014U, Policy (TN Multi - Gen), Dept. of. Education, Government of India, dt, 09-10-2018.

\section{REFERENCES}

1. Sale, D. G., Jacobs, I., MacDougall, J. D., \& Garner, S. (1990). Comparison of two regimens of concurrent strength and endurance training. Medicine and science in sports and exercise, 22(3), 348-356.

2. Tanaka, H., \& Swensen, T. (1998). Impact of resistance training on endurance performance. Sports medicine, 25(3), 191-200.

3. Nelson, A.G., Arnall, D.A., Loy, S.F., Silvester, L.J., Conlee, R.K. (1990). Consequences of combining strength and endurance training regimens. Phys Ther, 70(5):287-94.

4. Bell, G. J., Petersen, S. R., Wessel, J., Bagnall, K., \& Quinney, H. A. (1991). Physiological adaptations to concurrent endurance training and low velocity resistance training. International journal of sports medicine, 12(04), 384-390.

5. McCarthy, J.P. (1995). Compatibility of adaptive responses with combining strength and endurance training. Medicine and Science in Sports and Exercise, 27, 429-436.

6. Sale, D.G. (1988). Neural adaptation to resistance training. Med. Sci. Sports Exerc, 20 ( Suppl): S135- S145.

7. Hickson, R.C._(1980). Interference of strength development by simultaneously training for strength and endurance. Eur J Appl Physiol Occup Physiol, 45(2-3):255-63. 
8. Hunter, G., Demment, R., \& Miller, D. (1987). Development of Strength and Maximum Oxygen Uptake During Simultaneous Training For Strength and 14

9. Kraemer, W. J., Patton, J. F., Gordon, S. E., Harman, E. A., Deschenes, M. R., Reynolds, K. A. T. Y., ... \& Dziados, J. E. (1995). Compatibility of high-intensity strength and endurance training on hormonal and skeletal muscle adaptations. Journal of applied physiology, 78(3), 976-989.

10. Dudley, G. A., \& Djamil, R. U. S. D. A. N. (1985). Incompatibility of endurance-and strength-training modes of exercise. Journal of applied physiology, 59(5), 1446-1451.

11. Moritani, T. (1992). Time cource of adaptations during strength and power training. In strength and power in sports, ed. P.V. Komi,pp. 266 - 278: Oxford: BlackwellScientific.

12. Sale D.G. (1987). Influence of exercise and training motor unit activation. Excerc. Sports Sci. Rev. 15: 95- 151,

13. Maniazhagu, D., \& Susai Arokiamalar. (2012). Quantification of selected motor ability components, Physiological and Hematological responses to concurrent endurance trainining and circuit resistance training sequence among college men students. Unpublished Ph. D, thesis, Alagappa University, India.

14. Leveritt, M., Abernethy, P.J., Barry, B., Logan, P.A. (2003). Concurrent strength and endurance training: the influence of dependent variable selection. J Strength Cond Res, 17(3): 503-8. 